\title{
Cost and burden of informal caregiving of dependent older people in a rural Indian community
}

\author{
Ethel M Brinda ${ }^{1,2}$, Anto P Rajkumar ${ }^{1,3^{*}}$, Ulrika Enemark ${ }^{2}$, Jørn Attermann ${ }^{2}$ and KS Jacob ${ }^{1}$
}

\begin{abstract}
Background: Lack of state supported care services begets the informal caregiving by family members as the mainstay of care provided to the dependent older people in many Low and Middle Income Countries (LMICs), including India. Little is known about the time spent on caregiving, its cost and the burden experienced by these informal caregivers. We aimed to estimate the costs of informal caregiving and to evaluate the nature as well as correlates of caregivers' burden in a rural Indian community.

Methods: We assessed 1000 people aged above 65 years, among whom 85 were dependent. We assessed their socioeconomic profiles, disability, health status and health expenditures. Their caregivers' socio-demographic profiles, mental health, and the time spent on caregiving were assessed using standard instruments. Caregiver's burden was evaluated using Zarit Burden Scale. We valued the annual informal caregiving costs using proxy good method. We employed appropriate non-parametric multivariate statistics to evaluate the correlates of caregivers' burden.

Results: Average time spent on informal caregiving was 38.6 (95\% Cl 35.3-41.9) hours/week. Estimated annual cost of informal caregiving using proxy good method was 119,210 US\$ in this rural community. Mean total score of Zarit burden scale, measuring caregivers' burden, was 17.9 (95\% Cl 15.6-20.2). Prevalence of depression among the caregivers was 10.6\% (95\% Cl 4.1-17.1\%). Cerebrovascular disease, Parkinson's disease, higher disability, insomnia and incontinence of the dependent older people as well as the time spent on helping Activities of Daily Living and on supervision increased caregiver's burden significantly.

Conclusions: Cost and burden of informal caregiving are high in this rural Indian community. Many correlates of burden, experienced by caregivers, are modifiable. We discuss potential strategies to reduce this burden in LMICs. Need for support to informal caregivers and for management of dependent older people with chronic disabling diseases by multidisciplinary community teams are highlighted.
\end{abstract}

Keywords: Caregiver, Costs, Proxy good method, Activities of Daily Living

\section{Background}

Population ageing is a global phenomenon, which is related with increased life expectancy and transitions in disease pattern. With the steady increase in dependent older population [1], greater demand for health services and increased health care expenditures are expected to constrain the economies of many Low and Middle Income Countries (LMICs) [2]. The potential support ratio, which

\footnotetext{
* Correspondence: apr@hum-gen.au.dk

'Department of Psychiatry, Christian Medical College, Vellore 632002, India

${ }^{3}$ Department of Biomedicine, Aarhus University, Aarhus 8000, Denmark

Full list of author information is available at the end of the article
}

is defined as the number of working-age persons aged (15-64 years) per one older person aged above 65 years, is projected to fall from current nine to four working persons by 2050 [3]. Higher dependency ratios resulting from ageing of the population will demand high economic resource consumption for caregiving.

Implications of dependency, in terms of supportive care arrangements, have different contexts in high-income countries and in LMICs. High income countries support formal caregiving to dependent older people through institutional or home aided health services and social services [4]. However, the dependent older people in many 
LMICs rely on their family members due to the absence of social security systems and of any formal care support. Their informal caregivers continue to provide care without any financial or physical assistance from the state. Informal caregivers in high-income countries suffer high physical, psychological and financial burden [5-7]. Their quality of life and work participation deteriorate [8,9]. Although these issues are more relevant to LMICs, pertinent research in LMICs remain sparse.

Pearlin's stress process [10] and Yate's stress appraisal models [11] help the theoretical understanding of caregiving burden. Knowledge on determinants of caregivers' burden is essential to plan optimal interventions to alleviate the burden [6]. Several studies have investigated psychosocial factors [12,13], functional dependency and role conflicts [14] as the determinants of caregiving burden. However, different contexts in LMICs and cultural factors make these results less generalizable to LMICs [15]. As predictors of caregiving outcomes include sociodemographic characteristics, care needs, and time spent on caregiving among Asians [16], we aimed to evaluate these factors as the correlates of caregivers' burden in our population.

From societal and health policy perspective, it is necessary to estimate the costs of informal caregiving $[6,17]$. Prior studies in LMICs, have evaluated the costs of informal care for specific disease, with little focus on informal caregivers of dependent older people $[18,19]$. Dearth of health economic research on informal caregiving of dependent older people in LMICs has led to lack of policies supporting the needs and rights of informal caregivers. Hence, we aimed to estimate the cost of informal caregiving and to investigate the factors associated with burden among caregivers of dependent older people in a rural Indian community.

\section{Methods \\ Study design}

We employed a cross-sectional study design to evaluate our objectives. This study was a part of 10/66 Dementia Research Group population based studies [20]. The methodology employed in this study is briefly mentioned here and has been reported elsewhere in detail [21].

\section{Setting}

Kaniyambadi block of Vellore district is in the southern Indian state of Tamil Nadu. The Department of Community Health, Christian Medical College, Vellore, operates a community health program in this block for the past six decades. It has developed a four tier monitoring and a computerized health surveillance system of the residents of Kaniyambadi block. The community health workers, who live in the villages with the local community, provide detailed health statistics [22].
They are supervised by public health nurses and by physicians.

\section{Recruitment of participants}

Participants above the age of 60 years were first identified using a computerised list and by door-to-door survey. All consecutive older people, aged 65 years and above, who consented, were enrolled as participants. We have already reported the factors associated with dementia [21], depression [23], disability [15] and with out-ofpocket health expenditures [24] among these participants $(\mathrm{N}=1000)$. The dependent older people $(\mathrm{n}=85)$, who required care, and their primary caregivers $(\mathrm{N}=85)$ were identified among the study participants with the following eligibility criteria: (i) the older person was functionally dependent [25] and was unable to perform at least one of the Activities of Daily Living (ADL), including bathing, dressing, grooming, toileting, walking and feeding, without external help, (ii) he/she had a primary caregiver who provided assistance for ADL and accompanied him/her to health facilities, (iii) both the older person and his/her primary caregiver were willing to participate. A part of these caregiving dyads $(n=30)$, who satisfied the education adjusted 10/66 diagnostic criteria for dementia, have been previously included in the 10/66 cross-national investigation of correlates of burden among caregivers of older people with dementia in LMICs [13].

\section{Caregivers' assessment}

The following standard instruments were used to assess the caregivers: (i) Zarit Burden Interview (ZBI) [26] to assess their burden due to caregiving. It comprises 22 items, rated on 0-4 Likert scales. Total scores of ZBI range between 0 and 88 and higher scores indicate higher burden; (ii) Self-Reporting Questionnaire (SRQ) [27] to screen for psychiatric morbidity and depression. SRQ has 20-items, which are scored 0 or 1 . Total scores of five and above screen for common mental disorders [28] and a score of eight and above identifies depression in community [29]. SRQ has been used to detect common mental disorders in primary care in India [30]; (iii) Client Service Receipt Inventory [31,32] to elicit the information of caregivers' occupation, their absenteeism to provide care, their unpaid care time inputs and their income from all sources; (iv) Caregiver Activity Survey [33] to assess their time spent on ADL and on other care activities such as communication as well as supervision; (v) a structured proforma to assess caregiver's socio-demographic and socioeconomic characteristics. We assessed one randomly selected co-resident family member of each older person, who is not dependent ( $\mathrm{n}=915)$, with SRQ and recorded their socio-demographic characteristics for further comparisons. 


\section{Care recipients' assessment}

We assessed the dependent older participants with the following: (i) World Health Organization Disability Assessment Scale II (WHODAS II) [34] to measure the disability; (ii) Community Screening Instrument for Dementia (CSID) [35]; (iii) Neuro Psychiatric Inventory Questionnaire (NPI-Q) [36]; (iv) Geriatric Mental State (GMS) [37]; (v) History and Aetiology Schedule- Dementia Diagnosis and subtype (HAS-DDS) [38]; (vi) Client Socio-demographic and Service Receipt Inventory (CSSRI) [32] to assess the time spent on caregiver accompanied travel to various health services and time spent with health care personnel; (vii) structured questionnaire to assess the sociodemographic, socioeconomic, medical history and anthropometrics. Training of research staff involved the procedures for data collection and quality control, which were in accordance with the norms for 10/66 Dementia Research Group population studies [20,21]. The Institutional Review Board of Christian Medical College, Vellore, India, approved this study.

\section{Valuation of informal caregiving}

We initially estimated the amount of time (hours/week) spent on informal caregiving such as assistance with ADL $\left(\mathrm{T}_{\mathrm{ADL}}\right)$, health service utilization $\left(\mathrm{T}_{\mathrm{HSU}}\right)$, and other activities $\left(\mathrm{T}_{\mathrm{OA}}\right)$. As the revealed preference methods are preferred to evaluate informal caregiving costs [39], we valued the time spent on informal caregiving with one of the revealed preference methods, the Proxy Good method, that values time at the market wage rate of a professional substitute $[39,40]$. In the absence of national formal care aids, a multipurpose health worker (MPHW) seemed as a good proxy [41] and their nominal wages per hour in 2012 were 37.5 Indian Rupees (INR) (0.7 US\$) [42]. Using the proxy good method, we estimated the annual cost of informal caregiving $\left(\mathrm{C}_{\mathrm{IFC}}\right)$ as:

$$
\begin{aligned}
& T_{I F C}=\sum\left(T_{A D L}+T_{H S U}+T_{O A}\right) \\
& C_{I F C}=T_{I F C} * W R *(365 / 7)
\end{aligned}
$$

$\mathrm{T}_{\text {IFC }}$ is the total time spent on informal care activities per week and WR is the regional wage rate per hour of MPHW. Secondly, we estimated the expected growth of Indian Gross Domestic Product (GDP) with the accrual of the time lost in informal caregiving. This was estimated as a product of labor productivity (in terms of GDP per hour worked) and time spent in informal caregiving (hours/year). The labor productivity per hour in India is 3.8 US\$ [43]. All costs were adjusted to Indian rupee rates using the consumer price index in 2012 [44].

\section{Statistical analyses}

We initially analyzed the study variables using descriptive statistics. We employed logistic regression models to evaluate the factors associated with dependency among the older participants. We used Spearman rank order correlation to assess the correlation between ZBI and SRQ total scores. The distribution of our dependent variable, ZBI total score, did not follow Gaussian distribution and had influential outliers. Regression diagnostics indicated that employing ordinary least squares (OLS) regressions for evaluating the correlates of caregivers' burden would not be valid. Hence, we employed non-parametric robust regression by STATA rreg command to study the association between caregiver's burden and hypothesized variables. This method is robust to outliers and non-normality of residuals. It works iteratively performing OLS regression to compute case weights based on absolute residuals and regresses again using these weights until convergence. We assessed the coefficients of determination of our robust regression models by STATA rregfit command. We performed all analyses using statistical software STATA 12.1.

\section{Results}

\section{Caregivers' and care recipients' characteristics}

We present the details of recruitment of dependent older participants in Figure 1. Among 1000 older participants, the majority were women $(n=546 ; 54.6 \%)$ and those who lacked formal education ( $\mathrm{n}=661 ; 66.1 \%)$. Their $(\mathrm{N}=1000)$ mean age was 72.7 (SD 5.8) years and their mean WHODAS II total score was 23.39 (SD 8.39). Further sociodemographic and clinical data of all older participants $(\mathrm{N}=1000)$ have been published elsewhere [23]. We identified 85 functionally dependent older participants and included those 85 caregiving dyads in this study. Mean age of the dependent older participants $(\mathrm{n}=85)$ was 74.3 (SD 6.7) years. Female gender ( $\mathrm{n}=56$; OR = 1.7; 95\% CI 1.1-2.7; $\mathrm{p}=0.03$ ), lacking formal education $(\mathrm{n}=75 ; \mathrm{OR}=4.7 ; 95 \%$ CI 2.3-9.4; $\mathrm{p}<0.001)$, past occupation as manual laborers $(\mathrm{n}=78$; OR $=2.5$; $95 \%$ CI 1.1-5.6; $\mathrm{p}=0.02)$, cerebrovascular disease $(\mathrm{n}=8$; $\mathrm{OR}=$ 31.6; 95\% CI 8.2-121.5; $\mathrm{p}<0.001)$, dementia $(\mathrm{n}=4$; OR = 11.2; 95\% CI 2.7-45.8; $\mathrm{p}<0.001)$, falls $(\mathrm{n}=7 ; \mathrm{OR}=20.4$; 95\% CI 5.8-71.3; p p <0.001) and incontinence $(\mathrm{n}=13$; $\mathrm{OR}=54.9 ; 95 \%$ CI 15.3-197.0; $\mathrm{p}<0.001$ ) were significantly associated with functional dependence, while comparing the dependent older people $(n=85)$ with the independent older people $(n=915)$. Mean WHODAS II total score of dependent older participants was 35.2 (SD 13.5). We present the characteristics of their informal caregivers in Table 1. Most caregivers were women, lived with their care recipients and reported of suffering financial difficulties.

\section{Time spent on informal caregiving and its cost}

The mean time spent on informal caregiving was 38.6 (SD 15.4) hours/week. We present more details on the informal caregiving time and their costs in Table 2. The 


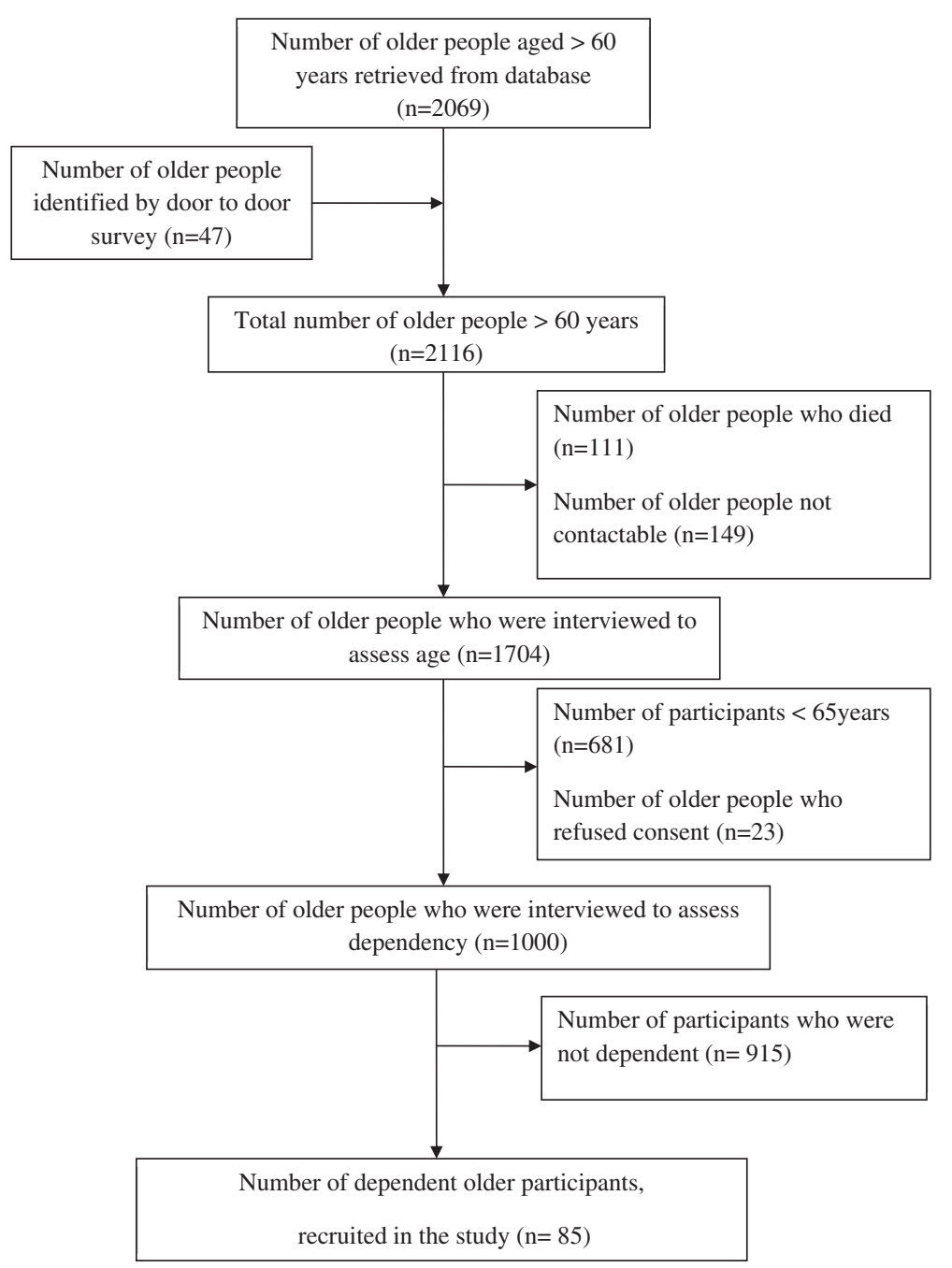

Figure 1 Recruitment of dependent older participants.

Table 1 Characteristics of caregivers providing informal care $(\mathbf{n}=\mathbf{8 5})$

\begin{tabular}{lcc}
\hline Caregivers' characteristics & n (\%) & Mean (SD) \\
\hline Age in years & $44.2(14.1)$ \\
Women as caregiver & $68(80.0)$ & \\
No formal education & $46(54.1)$ & \\
Reported per capita monthly family & & \\
income (in INR) & & \\
Co-residence with the care recipient & $74(87.1)$ & \\
Reported financial difficulties due to & $36(42.4)$ & \\
caregiving & \\
Reported difficulties with social life due & $20(23.6)$ & \\
to caregiving & \\
Need for additional caregiver & $54(63.5)$ & \\
Paid caregivers & $0(0)$ & \\
Sleep disturbance secondary to caregiving & $29(34.1)$ \\
Suicidal ideation secondary to caregiving & $8(9.4)$ \\
\hline
\end{tabular}

INR = Indian Rupees. estimated total annual cost of informal caregiving to these older participants $(n=85)$ was $119,210.2$ US\$. If the time, spent by these informal caregivers $(n=85)$ in a year, were added to the productive labor working hours, the GDP of the nation could increase by $649,902.6$ US\$ (3.8 US\$/hour*171027 hours).

\section{Nature of caregivers' burden}

Mean ZBI total score was 17.9 (SD 10.6). Among caregivers, 63.5\% $(\mathrm{n}=54)$ reported being unhappy, $21.2 \%$ $(\mathrm{n}=18)$ reported lacking time for themselves, and $20.1 \%(n=17)$ reported losing of control of their own lives due to their caregiving activities. We identified 40 (47.1\%) caregivers, who were at risk for common mental disorders. Prevalence of depression among these caregivers was $10.6 \%$ (95\% CI 4.1-17.1\%). Total SRQ scores (Median $=4 ; \mathrm{IQR}=3$ ) among caregivers of dependent older people $(n=85)$ were significantly higher (MannWhitney $U=30924.0 ; p=0.002)$ than the SRQ scores 
Table 2 Time spent on caregiving activities and cost of informal caregiving $(\mathbf{n}=\mathbf{8 5})$

\begin{tabular}{|c|c|c|c|c|c|}
\hline \multirow[t]{2}{*}{ Care activities } & \multirow[t]{2}{*}{$\begin{array}{l}\text { Time spent on care } \\
\text { giving mean (SD) }\end{array}$} & \multicolumn{2}{|c|}{$\begin{array}{c}\text { Annual costs }{ }^{\mathrm{a}} \text { of informal caregiving } \\
\text { mean (SD) }\end{array}$} & \multicolumn{2}{|c|}{ Total annual costs of informal caregiving } \\
\hline & & In Indian rupees & In US dollars & In Indian rupees & In US dollars \\
\hline Activities of Daily Living ${ }^{b}$ & 27.2 (8.9) (hours/week) & 53139.7 (17468.9) & $987.7(324.7)$ & 4516875.0 & 83956.8 \\
\hline Health Service Utilization ${ }^{c}$ & 17.6 (29.9) (minutes/week) & $574.4(975.4)$ & $10.7(18.1)$ & 48821.3 & 907.4 \\
\hline Other activities ${ }^{d}$ & 11.1 (10.8) (hours/week) & $21738.9(21151.3)$ & $404.1(393.1)$ & 1847812.5 & 34345.9 \\
\hline Total & 38.6 (15.3) (hours/week) & $75453.0(30075.2)$ & $1402.5(559.0)$ & 6413508.8 & 119210.2 \\
\hline
\end{tabular}

aproxy good method to value the informal care time close to a market price of a professional substitute; ${ }^{\text {b }}$ Time spent on Activities of Daily Living- includes time spent on assisting the older care recipient to eat, dress, look after their appearance, toileting and bathing; ${ }^{\mathrm{C}}$ Time spent to accompany the older care recipient, while travelling to health facilities and utilizing the health services; ${ }^{d}$ Time spent on supervision and helping with communication of the older care recipient. Conversion value of One US dollar = 53.8 Indian rupees, according to values recorded on 25.02.2013.

(Median = 3; IQR = 3) of the family members of other older participants, who were not dependent $(n=915)$. After adjusting for the effects of age, gender and education, the informal caregiving role significantly worsened mental health, as evidenced by higher SRQ total scores $(\beta=0.8 ; 95 \% C I=0.3-1.3 ; p=0.002)$. Total ZBI scores and SRQ total scores were correlated significantly among caregiving women (Spearman's $\rho=0.2, \mathrm{p}=0.04$ ). While adjusting for the effects of caregivers' gender, higher burden due to caregiving led to significantly worse mental health, as evidenced by higher SRQ total scores $(\beta=0.04 ; 95 \% C I=0.0006-0.08 ; p=0.04)$.

\section{Correlates of caregivers' burden}

We present both bivariate and multivariate analyses for the correlates of caregivers' burden in Table 3. Cerebrovascular disease, Parkinson's disease, higher disability, urinary incontinence, insomnia, and longer hours of informal caregiving significantly worsened caregivers' burden. A multivariate model including these significant correlates could account for $32 \%$ of the variability among the burden experienced by caregivers $\left(R^{2}=0.32\right)$.

\section{Discussion}

Our study estimated the cost of informal caregiving and examined the correlates of caregivers' burden in a rural Indian community. We used standard instruments to evaluate the time spent and burden experienced by informal caregivers. The possibility of recall bias was minimized by collaborating with local community health workers and by verifying available medical records. We acknowledge the following limitations. Our valuation methods led to conservative estimates. Our data included only the time spent by caregivers in assisting ADL, supervision, communication, transportation and utilization of health services. However, data on time spent on performing instrumental daily activities (IADL) and on health care activities for chronically ill older people were not available. Indirect costs due to negative health consequences of caregiving were not included. Hence, the actual cost of informal caregiving might be higher in this community. Our cross-sectional study design could not establish any causal associations.

\section{Cost of informal caregiving}

Despite using conservative estimates, the annual cost of informal caregiving of dependent older people in one rural Indian community $(n=85)$ was valued as 119,210.2 US\$. As there are more than five million dependent older people in India, the estimation of annual national cost on informal caregiving can be very high [45]. Formal care services for dependent older people in high-income countries, as compared to informal caregiving, were evaluated to be cost-effective [46]. They increase women's labor participation [47]. Loss of productive yield by the caregivers, who refrained from work, can affect a country's economy. Evaluation of cost effectiveness of caregiving services in any LMIC needs to consider the nation's productivity and the cost incurred by the loss of working population. The labor productivity loss of Indian GDP due to the time spent in informal caregiving by these caregivers $(n=85)$ amounted to $649,902.6$ US\$. Hence, production output that can be contributed to the nation's economy by the informal caregivers may surpass the state expenditures on formal caregiving services for dependent older people.

\section{Burden due to informal caregiving}

Caregivers' burden predicts the physical and mental health outcomes of dependent older people and their caregivers [6]. Informal caregiving demands substantial effort, productive time and financial resources of caregivers. With extended hours of caregiving, caregivers may develop sleep disturbance, depression, and chronic diseases [6]. Our study adds evidence that the burden of informal caregiving worsens the mental health of caregivers, especially the women. Thus, provision of informal caregiving proceeds at the expense of caregivers' wellbeing. Declining wellbeing of caregivers can lead to poor care of the dependent older people [48]. Neglecting to address the informal caregivers' burden may eventually lead to ineffective care of the disabled older people in LMICs. 
Table 3 Factors associated with caregivers' burden $(n=85)$

\begin{tabular}{|c|c|c|c|c|}
\hline Explanatory variables & $\beta^{\mathrm{a}}(95 \% \mathrm{Cl})$ & $\mathrm{p}$ value & $\beta^{b}(95 \% \mathrm{Cl})$ & $p$ value \\
\hline \multicolumn{5}{|l|}{ Care recipients' characteristics: } \\
\hline Age in years & $-0.1(-0.5 ;+0.2)$ & 0.41 & $-0.1(-0.4 ;+0.2)$ & 0.45 \\
\hline Male gender & $+4.3(-0.1 ;+8.8)$ & 0.06 & $+3.6(-1.2 ;+8.5)$ & 0.14 \\
\hline Household size & $-0.3(-1.1 ;+0.5)$ & 0.47 & $-0.2(-1.0 ;+0.6)$ & 0.63 \\
\hline Receives pension support & $-4.5(-9.5 ;+0.6)$ & 0.08 & $-4.0(-9.3 ;+1.2)$ & 0.13 \\
\hline Sleep disturbance & $+4.8(+0.5 ;+9.1)$ & 0.03 & $+5.5(+1.3 ;+9.8)$ & 0.01 \\
\hline Had experienced fall more than once & $+2.7(-5.1 ;+10.5)$ & 0.49 & $+2.86(-5.1 ;+10.8)$ & 0.47 \\
\hline Urinary Incontinence & $+6.9(+1.0 ;+12.7)$ & 0.02 & $+7.8(+1.4 ;+13.5)$ & 0.02 \\
\hline Diabetes mellitus & $-0.01(-6.0 ;+6.0)$ & 0.99 & $-0.6(-6.8 ;+5.6)$ & 0.85 \\
\hline Cerebro vascular disease & $+8.3(+1.4 ;+15.1)$ & 0.02 & $+7.5(0.4 ;+14.7)$ & 0.04 \\
\hline Parkinson's disease ${ }^{c}$ & $+15.3(+4.1 ;+26.4)$ & 0.008 & $+15.7(+4.1 ;+27.5)$ & 0.009 \\
\hline Dementia $^{d}$ & $+0.6(-10.8 ;+9.6)$ & 0.9 & $+0.007(-10.3 ;+10.3)$ & 0.99 \\
\hline WHODAS II total score ${ }^{e}$ & $+0.2(+0.04 ;+0.3)$ & 0.01 & $+0.2(+0.07 ;+0.4)$ & 0.004 \\
\hline \multicolumn{5}{|l|}{ Caregivers' characteristics: } \\
\hline Age in years & $+0.1(-0.03 ;+0.2)$ & 0.12 & $+0.1(-0.004 ;+0.3)^{f}$ & 0.13 \\
\hline Women as primary caregiver & $-0.6(-6.0 ;+4.8)$ & 0.83 & $+0.5(-5.0 ;+6.1)^{9}$ & 0.84 \\
\hline Spouse as primary caregiver & $+6.0(+1.1 ;+10.9)$ & 0.02 & $+5.8(-0.6 ;+12.2)$ & 0.08 \\
\hline Lack of formal education & $+0.1(-4.4 ;+4.6)$ & 0.96 & $-0.6(-5.3 ;+4.1)^{\mathrm{h}}$ & 0.79 \\
\hline Need to cut down work & $+0.06(-0.7 ;+8.3)$ & 0.87 & $+0.2(-0.7 ;+1.1)$ & 0.61 \\
\hline Availability of additional caregiver & $-1.3(-5.8 ;+3.2)$ & 0.57 & $-1.0(-5.7 ;+3.8)$ & 0.68 \\
\hline Hours/week of informal care on $A D L^{i}$ & $+1.8(0.2 ;+3.4)$ & 0.03 & $+1.8(+0.1 ; 3.5)$ & 0.03 \\
\hline Hours/week spent on supervision & $+6.7(+2.9 ;+10.4)$ & 0.001 & $+6.3(+2.5 ;+10.1)$ & 0.001 \\
\hline
\end{tabular}

Robust regression models with Zarit caregiver burden total score as dependent variable and the explanatory variable, presented in that row, as the only independent variable; ${ }^{\mathrm{b}}$ Multiple Robust regression models including Zarit caregiver burden total score as dependent variable, the explanatory variable, presented in that row, as the independent variable, and age, gender as well as education of caregivers as covariates; 'Reported as diagnosed with Parkinson's disease and

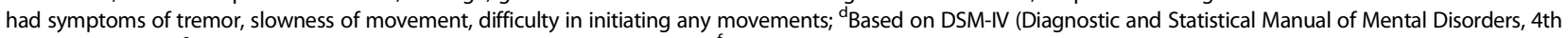
edition) diagnosis; ${ }^{~}$ WHO Disability Assessment Scale II 12 items total score; ${ }^{\mathrm{f}}$ Multiple Robust regression model including Zarit caregiver burden total score as dependent variable and age as the independent variable, that was adjusted for gender and education of caregivers as covariates; ${ }^{9}$ Multiple Robust regression models including Zarit caregiver burden total score as dependent variable and female gender as the independent variable, that was adjusted for age and education of caregivers as covariates; ${ }^{h}$ Multiple Robust regression models including Zarit caregiver burden total score as dependent variable and the lack of formal education as the independent variable, that was adjusted for age and gender as covariates 'Time spent in assisting the activities of daily living; Statistically significant associations with $\mathrm{p}$ vales $<0.05$ are presented in bold.

Our findings were consistent with the known predictors of caregivers' burden in high-income countries [10,11]. Our results confirmed that primary stressors (functional disability) and primary appraisal (informal caregiving hours) were significantly associated with caregivers' burden. Consistent with previous studies, stroke [18], Parkinson's disease [49], and urinary incontinence [50] increased caregivers' burden. An earlier cross-national study in LMIC reported that the burden of caregivers of older people with dementia was significantly associated with time spent on ADL, behavioral and psychological symptoms of dementia, and incontinence [13]. Our results confirmed these associations among caregivers of all dependent older people, regardless of their cognitive impairment, with appropriate non-parametric statistical models. Cost effective formal health and social services may modify these risk factors to reduce informal caregivers' burden and to help dependent older people.

\section{Why does informal caregiving prevail as a paradigm} in LMICs?

Despite well-established cost effectiveness of formal care services in high-income countries [46,47] and enormous burden suffered by informal caregivers in LMICs, many LMICs continue to persist with informal caregiving as their paradigm for caring dependent older people. The following may explain this discrepancy,

1. Culturally defined norms [51,52] oblige the family members to accept the care responsibilities as filial obligation towards older people [16]. Rural communities in LMICs hold diverse cultural beliefs that clinch family members responsible for caring dependent older people [53].

2. High gender inequality and gender stereotypes in patriarchal societies enforce the caregiving roles on many women [54]. Our study confirmed that most 
of the primary caregivers were women and that their mental health suffered due to caregiving burden.

3. Dearth of health economic research on informal caregiving in LMICs has left the pertinent problems under-recognized and unaddressed by policy makers in many LMICs. Social welfare support and care services to the dependent older people have not been prioritized in LMICs.

4. Health services in LMICs focus on acute management of diseases, while neglecting the need for long term disability management services [55]. Existing primary health care systems are designed to manage medical diseases and to prevent further disabilities. They are ill-equipped to care for the older people, who have already been disabled or dependent [56].

5. Rural health services do not include rehabilitative and palliative services in many LMICs.

6. Social services, which act in collaboration with health services to care for the dependent older people in high-income countries, do not exist or remain dysfunctional in many LMICs.

\section{Potential suggestions}

The universal declaration of human rights states that every human has the right for autonomy and social security [57]. Forcing the informal caregiving role on anyone, due to the absence of state sponsored formal care services, can be considered as a violation of human rights. Hence, we suggest the following,

1. Our study revealed that stroke and Parkinson's disease increased caregivers' burden.

Multidisciplinary teams including medical professionals, social workers, physiotherapists and occupational therapists are essential for managing chronic disabling diseases in communities. Costeffectiveness of such multidisciplinary community interventions for dependent older people has been documented [46].

2. Health services in LMICs should not stop with acute management of cerebrovascular accidents and with medical management of underlying risk factors. They should include rehabilitation and long-term care services for stroke survivors. Long-term rehabilitation services and periodic risk assessments may impede the progression of disability [58].

3. We identified that longer caregiving hours increased caregivers' burden. Respite services need to be implemented to help the caregivers, engaged in full-time caregiving. Provision of specialized aids and equipment, such as wheel chairs, in a subsidized cost may reduce dependency and caregiving time spent on ADL.
4. Caregiving women in this study population suffered poor mental health. Periodic educational and counseling programs as well as regular screening for psychiatric disorders are suggested for those caregiving women.

5. Dependent older people suffering insomnia and urinary incontinence led to significantly higher caregivers' burden. Direct enquiry and detailed assessment of underlying causes should be a part of primary care assessment and management.

Continence services [59] and financial assistance for continence products may reduce the burden suffered by the caregivers of incontinent older people.

6. Health services in any country cannot effectively care their dependent older people without social services assistance. Developing a functional social services system should be prioritized in LMICs to care for the dependent older people and to protect the rights of their caregivers.

7. Collaboration between public sector and nongovernmental organizations are essential to provide decentralized rehabilitative and palliative services to rural India.

\section{Conclusions}

Informal caregiving may remain as a voluntary contribution, by the motivated family members. However, reluctance of Governments to provide formal caregiving alternatives continues to coerce the vulnerable family members, especially the women, to assume caregiving roles in LMICs. There is an urgent need to care for the wellbeing of dependent older people and their families. Costs of informal caregiving should be included in the economic evaluations of health interventions and cost of illness studies in LMICs.

\section{Competing interests}

All authors declare that they have no competing interests.

\section{Authors' contributions}

$E M B, A P R$ and $K S J$ were involved in the conception of the research question. EMB developed the research question, performed the statistical analyses and drafted the manuscript. KSJ supervised the study and data collection. APR, JA, KSJ and UE contributed to data analysis, interpretation of results and manuscript revisions. All authors read and approved the final manuscript.

\section{Acknowledgement}

This study is a part of the population based investigations of the 10/66 Dementia Research group of Alzheimer's disease International. It was supported by grants from the World Health Organization and from the Institute of Psychiatry, London. We thank Prof. Martin Prince, all study participants as well as their families and the research fellows, Mr. Senthil Kumar, Ms. Gayathri, Ms. Kanagathara and Ms. Simon, for data collection.

\section{Source of funding}

This study is a part of the population based investigations of the 10/66 Dementia Research group of Alzheimer's disease International. It was supported by grants from the World Health Organization and from the Institute of Psychiatry, London. 


\section{Author details}

${ }^{1}$ Department of Psychiatry, Christian Medical College, Vellore 632002, India. ${ }^{2}$ Department of Public Health, Aarhus University, Aarhus 8000, Denmark. ${ }^{3}$ Department of Biomedicine, Aarhus University, Aarhus 8000, Denmark.

Received: 6 November 2013 Accepted: 25 April 2014 Published: 7 May 2014

\section{References}

1. UNICEF: Empower Women to Help Children. 2007. http://www.unicef.org/ media/media 37474.html.

2. UN: Development in an Ageing World. 2007. http://www.un.org/en/ development/desa/policy/wess/wess_archive/2007wess.pdf.

3. UN: Population Ageing and Development 2012. 2012. http://www.un.org/esa/ population/publications/2012WorldPopAgeingDev_Chart/2012PopAgeingand Dev_WallChart.pdf.

4. Talley RC, Crews JE: Framing the public health of caregiving. Am J Publ Health 2007, 97(2):224-228

5. Navaie-Waliser M, Feldman PH, Gould DA, Levine C, Kuerbis AN, Donelan K: When the caregiver needs care: the plight of vulnerable caregivers. Am J Public Health 2002, 92(3):409-413.

6. Carretero S, Garces J, Rodenas F, Sanjose V: The informal caregiver's burden of dependent people: theory and empirical review. Arch Gerontol Geriatr 2009, 49(1):74-79.

7. Arno PS, Levine C, Memmott MM: The economic value of informal caregiving. Health Aff (Millwood) 1999, 18(2):182-188.

8. Bevans M, Sternberg EM: Caregiving burden, stress, and health effects among family caregivers of adult cancer patients. JAMA 2012, 307(4):398-403.

9. Cooper C, Katona C, Orrell M, Livingston G: Coping strategies, anxiety and depression in caregivers of people with Alzheimer's disease. Int J Geriatr Psychiatry 2008, 23(9):929-936.

10. Pearlin LI, Mullan JT, Semple SJ, Skaff MM: Caregiving and the stress process: an overview of concepts and their measures. Gerontologist 1990, 30(5):583-594.

11. Yates ME, Tennstedt S, Chang BH: Contributors to and mediators of psychological well-being for informal caregivers. J Gerontol B Psychol Sci Soc Sci 1999, 54(1):12-22.

12. McCullagh E, Brigstocke $G$, Donaldson N, Kalra L: Determinants of caregiving burden and quality of life in caregivers of stroke patients. Stroke 2005, 36(10):2181-2186.

13. Prince $M$, Brodaty $H$, Uwakwe $R$, Acosta $D$, Ferri CP, Guerra M, Huang $Y$, Jacob KS, Llibre Rodriguez JJ, Salas A, Sosa AL, Williams JD, Jotheeswaran AT, Liu Z: Strain and its correlates among carers of people with dementia in low-income and middle-income countries. A 10/66 Dementia Research Group population-based survey. Int J Geriatr Psychiatry 2012, 27(7):670-682.

14. Nijboer C, Triemstra M, Tempelaar R, Sanderman R, van den Bos GA: Determinants of caregiving experiences and mental health of partners of cancer patients. Cancer 1999, 86(4):577-588.

15. Duba AS, Rajkumar AP, Prince M, Jacob KS: Determinants of disability among the elderly population in a rural south Indian community: the need to study local issues and contexts. Int Psychogeriatr 2012, 24(2):333-341.

16. Casado B, Sacco P: Correlates of caregiver burden among family caregivers of older Korean Americans. J Gerontol B Psychol Sci Soc Sci 2012, 67(3):331-336.

17. Feinburg LR, Susan C, Houser A, Choula R: Valuing the Invaluable: 2011 Update. The Growing Contributions and Costs of Family Caregiving. 2011 http://assets.aarp.org/rgcenter/ppi/ltc/i51-caregiving.pdf.

18. Riewpaiboon A, Riewpaiboon W, Ponsoongnern K, Van den Berg B: Economic valuation of informal care in Asia: a case study of care for disabled stroke survivors in Thailand. Soc Sci Med 2009, 69(4):648-653.

19. Srinivasa Murthy R, Kishore Kumar KV, Chisholm D, Thomas T, Sekar K, Chandrashekari CR: Community outreach for untreated schizophrenia in rural India: a follow-up study of symptoms, disability, family burden and costs. Psychol Med 2005, 35(3):341-351.

20. Prince M, Acosta D, Chiu H, Scazufca M, Varghese M: Dementia diagnosis in developing countries: a cross-cultural validation study. Lancet 2003, 361(9361):909-917.
21. Jacob KS, Kumar PS, Gayathri K, Abraham S, Prince MJ: The diagnosis of dementia in the community. Int Psychogeriatr 2007, 19(4):669-678.

22. Joseph A, Joseph KS, Kamaraj K: Use of computers in primary health care. Int J Healt Sci 1991, 2:93-101.

23. Rajkumar AP, Thangadurai $P$, Senthilkumar P, Gayathri K, Prince M, Jacob KS: Nature, prevalence and factors associated with depression among the elderly in a rural south Indian community. Int Psychogeriatr 2009, 21(2):372-378

24. Brinda EM, Rajkumar AP, Enemark U, Prince M, Jacob KS: Nature and determinants of out-of-pocket health expenditure among older people in a rural Indian community. Int Psychogeriatr 2012, 24(10):1664-1673.

25. Huang YC, Wueng SL, Ou CC, Cheng CH, Su KH: Nutritional status of functionally dependent and nonfunctionally dependent elderly in Taiwan. J Am Coll Nutr 2001, 20(2 Suppl):135-142.

26. Zarit SH, Reever KE, Bach-Peterson J: Relatives of the impaired elderly: correlates of feelings of burden. Gerontologist 1980, 20(6):649-655.

27. Mari JJ, Williams P: A comparison of the validity of two psychiatric screening questionnaires (GHQ-12 and SRQ-20) in Brazil, using Relative Operating Characteristic (ROC) analysis. Psychol Med 1985, 15(3):651-659.

28. Giang KB, Allebeck P, Kullgren G, Van Tuan N: The Vietnamese version of the Self Reporting Questionnaire 20 (SRQ-20) in detecting mental disorders in rural Vietnam: a validation study. Int J Soc Psychiatry 2006, 52(2):175-184

29. Harpham T, Huttly S, De Silva MJ, Abramsky T: Maternal mental health and child nutritional status in four developing countries. J Epidemiol Community Health 2005, 59(12):1060-1064.

30. Patel V, Araya R, Chowdhary N, King M, Kirkwood B, Nayak S, Simon G, Weiss HA: Detecting common mental disorders in primary care in India: a comparison of five screening questionnaires. Psychol Med 2008, 38(2):221-228.

31. Chisholm D, Knapp MR, Knudsen HC, Amaddeo F, Gaite L, van Wijngaarden B: Client socio-demographic and service receipt inventory-European version: development of an instrument for international research. EPSILON Study 5. European psychiatric services: inputs linked to outcome domains and needs. Br J Psychiatry Suppl 2000, (39):s28-s33.

32. Chisholm D, Sekar K, Kumar KK, Saeed K, James S, Mubbashar M, Murthy RS: Integration of mental health care into primary care. Demonstration costoutcome study in India and Pakistan. Br J Psychiatry 2000, 176:581-588.

33. Davis KL, Marin DB, Kane R, Patrick D, Peskind ER, Raskind MA, Puder KL: The Caregiver Activity Survey (CAS): development and validation of a new measure for caregivers of persons with Alzheimer's disease. Int J Geriatr Psychiatry 1997, 12(10):978-988.

34. WHO: WHODAS II Disability Assessment Schedule: 12-Item interviewer administered version. Geneva: World Health Organization; 2001

35. Hall KS, Gao S, Emsley CL, Ogunniyi AO, Morgan O, Hendrie HC: Community screening interview for dementia (CSI 'D'); performance in five disparate study sites. Int J Geriatr Psychiatry 2000, 15(6):521-531.

36. Cummings JL, Mega M, Gray K, Rosenberg-Thompson S, Carusi DA, Gornbein J: The neuropsychiatric inventory: comprehensive assessment of psychopathology in dementia. Neurology 1994, 44(12):2308-2314.

37. Copeland JR, Dewey ME, Griffiths-Jones HM: A computerized psychiatric diagnostic system and case nomenclature for elderly subjects: GMS and AGECAT. Psychol Med 1986, 16(1):89-99.

38. Dewey ME, Copeland JR: Diagnosis of dementia from the history and aetiology schedule. Int J Geriatr Psychiatry 2001, 16(9):912-917.

39. van den Berg B, Brouwer WB, Koopmanschap MA: Economic valuation of informal care. An overview of methods and applications. Eur J Health Econ 2004, 5(1):36-45

40. van den Berg B, Brouwer W, van Exel J, Koopmanschap M, van den Bos GA, Rutten F: Economic valuation of informal care: lessons from the application of the opportunity costs and proxy good methods. Soc Sci Med 2006, 62(4):835-845.

41. Shaji KS, Smitha K, Lal KP, Prince MJ: Caregivers of people with Alzheimer's disease: a qualitative study from the Indian 10/66 Dementia Research Network. Int J Geriatr Psychiatry 2003, 18(1):1-6.

42. NRHM-TN: Consolidated budget sheet for RCH flexi pool for the year 2011-12. 2012. http://www.nrhmtn.gov.in/roppdf/vellore11.pdf.

43. APO: Productivity Databook 2012. 2012. http://www.apo-tokyo.org/ publications/files/ind_APO_Productivity_Databook_2012.pdf.

44. RBI: RBI Bulletin-Consumer Price Index Numbers for Agricultural/Rural Labourers. 2012. http://www.rbi.org.in/scripts/BS_ViewBulletin.aspx?ld=13884 
45. WB: Data: Population ages 65 and above. 2012. http://data.worldbank.org/ indicator/SP.POP.65UP.TO.ZS

46. Melis RJ, Adang E, Teerenstra S, van Eijken MI, Wimo A, van Achterberg T, van de Lisdonk EH, Rikkert MG: Cost-effectiveness of a multidisciplinary intervention model for community-dwelling frail older people. $J$ Gerontol A Biol Sci Med Sci 2008, 63(3):275-282.

47. Viitanen TK: Informal and formal care in Europe. In IZA Discussion Papers No 2648. Germany: Institute for the Study of Labor; 2007.

48. Greenberger $\mathrm{HL}$, Litwin $\mathrm{H}$ : Can burdened caregivers be effective facilitators of elder care-recipient health care? J Adv Nurs 2003, 41(4):332-341.

49. D'Amelio M, Terruso V, Palmeri B, Di Benedetto N, Famoso G, Cottone P, Aridon P, Ragonese $P$, Savettieri G: Predictors of caregiver burden in partners of patients with Parkinson's disease. Neurol Sci 2009, 30(2):171-174.

50. Tamanini JT, Santos JL, Lebrão ML, Duarte YA, Laurenti R: Association between urinary incontinence in elderly patients and caregiver burden in the city of Sao Paulo/Brazil: Health, Wellbeing, and Ageing Study. Neurourol Urodyn 2011, 30(7):1281-1285.

51. Gupta R: Systems perspective: understanding care giving of the elderly in India. Health Care Women Int 2009, 30(12):1040-1054.

52. Gupta RP VK, Levy EF: Relationship quality and elder caregiver burden in India. 2012. http://www.journalsi.org/index.php/si/article/viewFile/285/265.

53. Kipp W, Tindyebwa D, Rubaale T, Karamagi E, Bajenja E: Family caregivers in rural Uganda: the hidden reality. Health Care Women Int 2007, 28(10):856-871.

54. del-Pino-Casado R, Frias-Osuna A, Palomino-Moral PA, Martinez-Riera JR: Gender differences regarding informal caregivers of older people. J Nurs Scholarship 2012, 44(4):349-357.

55. Kumar SG, Roy G, Kar SS: Disability and rehabilitation services in India: issues and challenges. J Fam Med Primary Care 2012, 1:69-73.

56. Kumar H, Gupta N: Neurological disorders and barriers for neurological rehabilitation in rural areas in Uttar Pradesh: a cross-sectional study. J Neurosci Rural Pract 2012, 3(1):12-16.

57. UN: The Universal declaration of human rights. 1948. http://www.un.org/en/ documents/udhr/\#atop.

58. Anderson C, Ni Mhurchu C, Brown PM, Carter K: Stroke rehabilitation services to accelerate hospital discharge and provide home-based care: an overview and cost analysis. Pharmacoeconomics 2002, 20(8):537-552.

59. NHS: Urinary incontinence: NICE clinical guideline 171. 2013. http://www.nice. org.uk/nicemedia/live/14271/65143/65143.pdf.

doi:10.1186/1472-6963-14-207

Cite this article as: Brinda et al:: Cost and burden of informal caregiving of dependent older people in a rural Indian community. BMC Health Services Research 2014 14:207.

\section{Submit your next manuscript to BioMed Central and take full advantage of:}

- Convenient online submission

- Thorough peer review

- No space constraints or color figure charges

- Immediate publication on acceptance

- Inclusion in PubMed, CAS, Scopus and Google Scholar

- Research which is freely available for redistribution 